\title{
Proceeding
}

Supplementary Issue: Spring Conferences of Sports Science. Costa Blanca Sports Science Events, 19-20 June 2020. Alicante, Spain.

\section{Can tongue position and cervical ROM affect postural oscillations? A pilot and preliminary study}

\author{
LUCA RUSSO 1,2, VALERIO GIUSTINO ${ }^{1,3} \triangleleft$, ROSARIO EMANUELE TOSCANO ${ }^{1}$, GIUSEPPE SECOLO ${ }^{1}$, \\ INNOCENZO SECOLO ${ }^{1}$, ANGELO IOVANE ${ }^{1,3}$, GIUSEPPE MESSINA ${ }^{1,3}$ \\ ${ }^{1}$ Laboratory of Posture and Biomechanics, University of Palermo, Palermo, Italy \\ 2Department of Biotechnology and Applied Clinical Science, University of L'Aquila, L'Aquila, Italy \\ ${ }^{3}$ Department of Psychology, Educational Science and Human Movement, University of Palermo, Palermo, \\ Italy
}

\begin{abstract}
The tongue is considered an important part of the postural system, so it is fundamental to understand how it can interfere with the humans' postural oscillations. The aim of this preliminary investigation is to understand the effects of different tongue position and cervical ROM on postural oscillations measured in a stabilometric test. Thirteen voluntary subjects were recruited $(30.8 \pm 9.7$ yrs.; $173.6 \pm 14.9 \mathrm{~cm} ; 72.6 \pm 15.6 \mathrm{~kg})$ and tested in three different random tongue conditions: comfortable tongue position (CT), palatal spot position (ST) and low tongue position (LT). All tests were performed with open eyes. Stabilometric test were performed with a pressure platform. In addition, the cervical ROM was assessed in the CT condition to create a baseline measurement and to find out baseline relationship with cervical ROM and postural oscillations. Data analysis indicates no significant difference in CoP sway path length for CT / ST / LT $(260.7 \pm 106.5 \mathrm{~mm} / 236.9 \pm 79.3 \mathrm{~mm} / 272.9 \pm 89.3 \mathrm{~mm}$, respectively). A moderate but significant correlation is present between postural oscillations and cervical rotation ROM $(R=-0.59 ; p=.03)$, indicating that good postural oscillations are connected with a free ROM of the highest part of the body. The results of this preliminary investigation do not support the use of different tongue position during postural assessment to discriminate some postural interferences of the tongue. At the same time the results suggest the relationship between cervical ROM and stability. These results suggest the necessity to study more in deep this phenomenon with other specific class of subjects.
\end{abstract}

Keywords: Posture; Stabilometry; Postural oscillations; Cervical ROM; Tongue position.

Cite this article as:

Russo, L., Giustino, V., Toscano, R.E., Secolo, G., Secolo, I., lovane, A., \& Messina, G. (2020). Can tongue position and cervical ROM affect postural oscillations? A pilot and preliminary study. Journal of Human Sport and Exercise, 15(3proc), S840-S847. doi:https://doi.org/10.14198/jhse.2020.15.Proc3.35

Corresponding author. Department of Psychology, Educational Science and Human Movement, University of Palermo, Palermo, Italy. https://orcid.org/0000-0002-4575-8021

E-mail: valerio.giustino@unipa.it

Supplementary Issue: Spring Conferences of Sports Science. Costa Blanca Sports Science Events, 19-20 June 2020. Alicante, Spain.

JOURNAL OF HUMAN SPORT \& EXERCISE ISSN 1988-5202

(c) Faculty of Education. University of Alicante

doi:10.14198/jhse.2020.15.Proc3.35

S840

| 2020| Proc3 | VOLUME 15

C 2020 University of Alicante 


\section{INTRODUCTION}

Body posture is controlled by the central nervous system through the interaction of multisensorial input of several postural receptors which are exteroceptive, interoceptive and proprioceptive organs as the vestibular and the visual system, and the muscular proprioceptive organs (Carini et al., 2017; Peterka, 2018; Proske and Gandevia, 2012). The scientific literature reports several researches that have shown changes on postural oscillations by evaluating postural receptors in different conditions (e.g., various visual input; changing auditory stimuli; different mandibular position) (Baldini et al., 2013; Chen and Qu, 2017). In this context, many research groups have investigated the role of the stomatognathic system, in terms of temporomandibular disorders, swallowing disorders, occlusion classes and tongue position on body posture (Julia-Sanchez et al., 2019; Perinetti et al., 2010; Solovykh, 2013). In particular, the tongue, through the biomechanical interaction between the anatomical structures of the stomatognathic system, plays a key role on body posture (Messina, 2017, 2020). Indeed, previous research demonstrated the influence of tongue posture and swallowing on postural control (Alghadir et al., 2015). Alghadir et al reported that the centre of gravity (CoG) velocity changed significantly in relation to different tongue position (Alghadir et al., 2015). Moreover, due to the biomechanical and myofascial connection, the tongue posture as well as the mandible position can affect many aspects of physical fitness as strength and mobility (G. Battaglia et al., 2016; G. Battaglia et al., 2018; Myers, 2001; Wilke et al., 2016).

Our hypothesis is that the change in the position of the tongue can affect postural behaviour in terms of oscillations. Furthermore, we suppose that the cervical range of motion (ROM) can influence postural stability. For this reason, the aim of this pilot and preliminary study is to assess separately postural stability during different tongue positions and cervical ROM in healthy subjects. Secondary, we investigate any relationship between these two parameters.

\section{METHODS}

\section{Participants}

Thirteen voluntary subjects were recruited (age: $30.8 \pm 9.7$ years; weight: $72.6 \pm 15.6 \mathrm{~kg}$; height $173.6 \pm$ $14.9 \mathrm{~cm}$ ). The exclusion criteria were: participants with muscular, neurological or tendinous injuries, participants with face deformities, neck or TMJ pain, vertigo or others dizziness symptoms. The inclusion criteria were: good global health. After a clinical evaluation performed by a skilled professional, the group was divided into two subgroups: 1) 7 subjects without swallowing disorders (WTSD), 2) 6 subjects with swallowing disorders (WSD). This division was performed in order to check different postural behaviour within these two clusters. Ethical approval was issued by the local University Ethics Committee in agreement with the Declaration of Helsinki. After being informed of the procedures, methods, benefits and possible risks involved in the study, each participant reviewed and signed an informed consent in accordance with the ethical standards.

\section{Experimental setting and measurements}

Testing was carried out in Laboratory of Posture and Biomechanics, University of Palermo, Palermo, Italy at the temperature of $23^{\circ} \mathrm{C}$ and relative humidity of $45 \%$ and at the same time of the day $(4 \mathrm{pm})$ to avoid any circadian effects (Russo et al., 2015).

All participants were tested during the same day in three different random tongue conditions: comfortable tongue position (CT), palatal spot position (ST), and low tongue position (LT). Each participant performed a stabilometric test in each of these conditions according to the international standardization criteria (Kapteyn 
et al., 1983): visual target within 5 meters head in neutral position, silence, first acquisition with open and then with closed eyes, each test was 51.2 seconds long, feet were positioned with heel separated of $2 \mathrm{~cm}$ and the feet tips $30^{\circ}$ wide apart, arms were close fitted to thighs. All the testes were performed with open eyes. Stabilometric test were performed on a pressure platform with a resistive sensors matrix (FreeMed $($, Sensor Medica $§$, Guidonia Montecelio, Italy), the accuracy of the instrument was previously documented (Romero-Franco et al., 2013; Russo et al., 2018). After the stability evaluation, the cervical ROM (Figure 1) was assessed for sagittal plane (flexion and extension), transversal plane (left and right rotation), coronal plane (left and right inclination). Cervical ROM test was performed using an inertial sensor (Moover®, Sensor Medica $\circledR$, Guidonia Montecelio, Italy) positioned in the middle of the forehead. The test was performed in standing position, the same used for stabilometry and in CT condition, to create a baseline measurement and to find out baseline relationship with natural cervical ROM and postural oscillations.
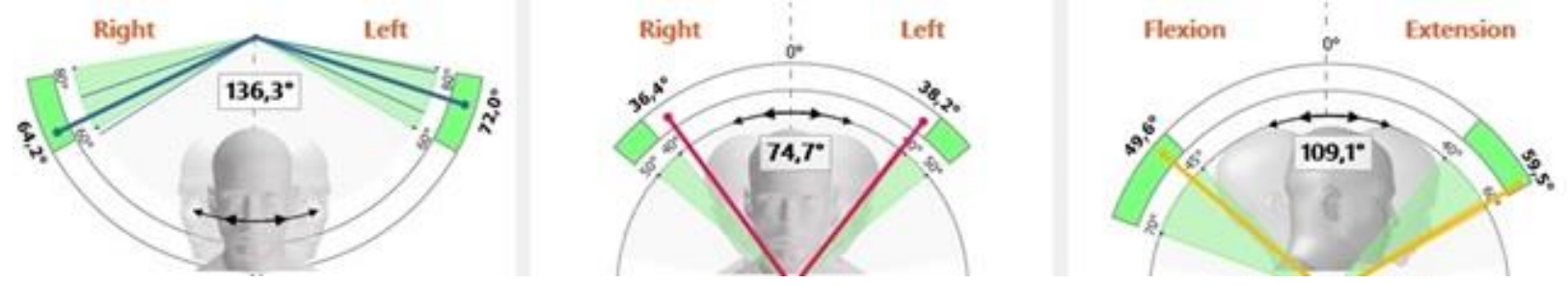

Figure 1. Cervical ROM. From left to right: transversal plane (rotation), coronal plane (inclination), sagittal plane (flexion and extension).

The following measurements were analysed: CoP sway path length for each stabilometric test in each condition and angle of cervical ROM on the three anatomical planes.

\section{Statistical analysis}

Data, presented as means and standard deviations $( \pm S D)$, were calculated after verifying the normality of distributions using the Shapiro-Wilk test (Shapiro and Wilk, 1965). Data were normally distributed, so parametric statistics was used. In order to determine significant differences in the two subgroups WTSD/WSD a t-test for independent sample was performed. In order to determine significant differences for different tongue position an analysis of variance (ANOVA) for repeated measures on one factor (tongue position) was applied. In order to determine a significant correlation between postural oscillations behaviour and cervical ROM a Pearson coefficient was calculated. Statistical analyses were performed using the software IBM $尺$ SPSS® Statistic version 21.0 (IBM Corporation, Somers, NY, USA). The level of significance was set at $p \leq$ .05 .

\section{RESULTS}

The descriptive statistics for stabilometric test in different conditions and for cervical ROM measurement are showed in Table 1 and Table 2 respectively.

WTSD and WSD groups were equal from a statistical point of view both for CoP sway path length and for cervical ROM angle, no statistical differences were measured between these two subgroups.

The entire group showed a lack of difference for the CoP sway path length between the three tongue positions. CT $(260.7 \pm 106.5 \mathrm{~mm})$, ST $(236.9 \pm 79.3 \mathrm{~mm})$, and LT $(272.9 \pm 89.3 \mathrm{~mm})$ showed very similar behaviour in terms of postural oscillations and no statistical differences were measured. Hence, the tongue 
position seems do not affect the posture; or the stabilometric test is not sufficient to discriminate the acute effect of tongue position on postural behaviour in standing position.

Table 1. Stabilometric data for each tongue position and for each participants group.

\begin{tabular}{cccc}
\hline $\begin{array}{c}\text { Tongue } \\
\text { position }\end{array}$ & $\begin{array}{c}\text { CoP Sway Path Length }(\mathrm{mm}) \\
\text { All subjects (13) }\end{array}$ & $\begin{array}{c}\text { CoP Sway Path Length } \\
(\mathbf{m m}) \text { WTSD subjects }(\mathbf{7})\end{array}$ & $\begin{array}{c}\text { CoP Sway Path Length } \\
(\mathbf{m m}) \text { WSD subjects (6) }\end{array}$ \\
\hline CT & $260.7 \pm 106.5$ & $247.0 \pm 100.7$ & $276.7 \pm 120.3$ \\
ST & $236.9 \pm 79.3$ & $203.1 \pm 35.4$ & $276.4 \pm 100.7$ \\
LT & $272.9 \pm 89.3$ & $254.8 \pm 58.3$ & $294.0 \pm 118.7$ \\
\hline
\end{tabular}

Legend. data are expressed as mean/SD for each parameter. CT: comfortable tongue position. ST: spot tongue position. LT: low tongue position. WTSD: without swallowing disorders. WSD: with swallowing disorders. No significant difference between any parameter $(p>.05)$.

Table 2. Cervical ROM data for each participants group.

\begin{tabular}{cccc}
\hline Groups & $\begin{array}{c}\text { Transversal Plane } \\
\text { Cervical ROM }\left({ }^{\circ}\right)\end{array}$ & $\begin{array}{c}\text { Coronal Plane } \\
\text { Cervical ROM }\left({ }^{\circ}\right)\end{array}$ & $\begin{array}{c}\text { Sagittal Plane } \\
\text { Cervical ROM }\left({ }^{\circ}\right)\end{array}$ \\
\hline All subjects (13) & $138.2 \pm 15.7$ & $76.7 \pm 18.0$ & $108.7 \pm 21.7$ \\
WTSD (7) & $136.1 \pm 14.7$ & $74.9 \pm 21.0$ & $110.2 \pm 22.1$ \\
WSD (6) & $140.5 \pm 17.8$ & $78.9 \pm 15.5$ & $106.9 \pm 23.2$
\end{tabular}

Legend. Data are expressed as mean/SD for each parameter. CT: comfortable tongue position. ST: spot tongue position. LT: low tongue position. WTSD: without swallowing disorders. WSD: with swallowing disorders. No significant difference between any parameter $(p>.05)$.

A moderate but significant correlation can be observed between postural oscillations and cervical rotation ROM (Figure 2), specifically between CoP sway path length and transversal plane range of motion $(R=-$ 0.59 and $p=.03$ ), no other significant relationship was measured. This connection between the dynamic motion of the head and the postural oscillations is very interesting because it represents the connection between the highest and the lowest part of the body.

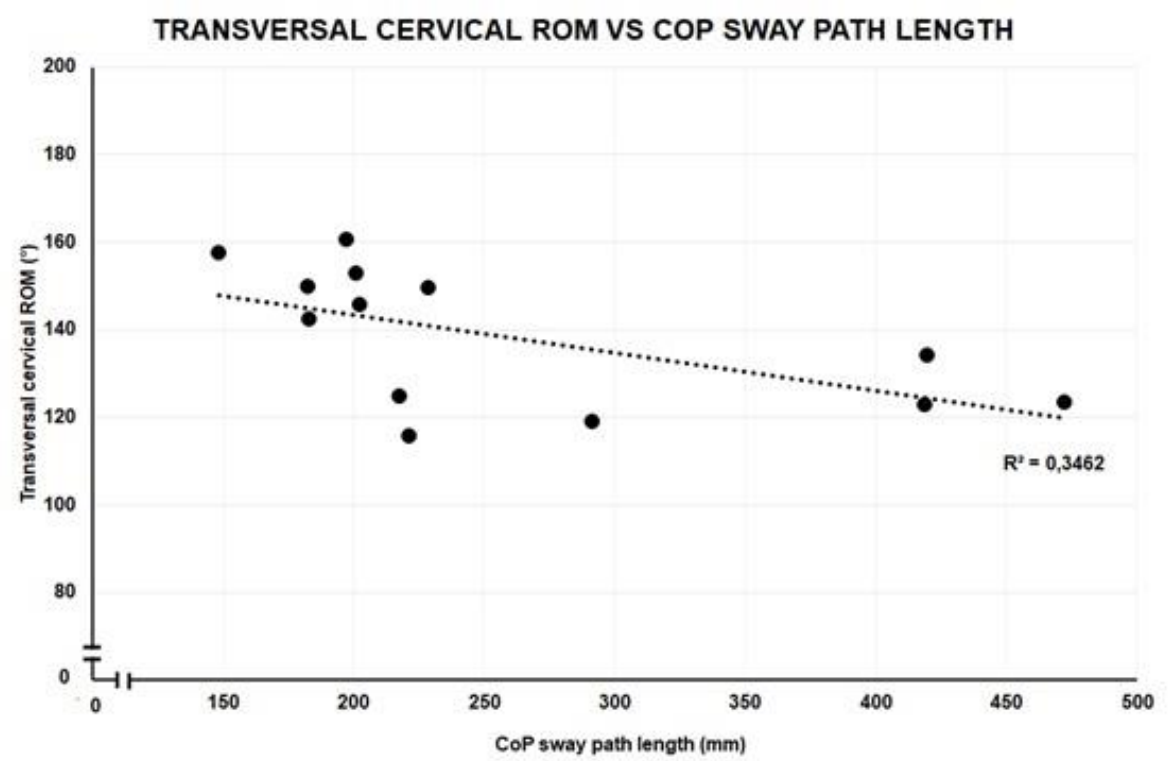

Figure 2. Transversal plane cervical ROM vs CoP sway path length, inverse significant relationship $(R=-$ $0.59 ; p=.03)$. In case of limitation in head rotation the CoP sway path length results increased. 


\section{DISCUSSION}

The aim of this pilot and preliminary study is to assess separately postural stability in different tongue conditions and cervical ROM in healthy subjects in order to find out any relationships. The tongue position is a postural characteristic and depends from several aspects (Gonzalez et al., 2019; Valentim et al., 2016). To investigate its effects on postural oscillations is fundamental in terms of postural assessment and treatment (Vuillerme et al., 2008). On the other hand, the quantity of degrees of freedom of neck and head, measured by the cervical ROM test, is another important issue in health and postural behaviour (G. Battaglia et al., 2016; Celenay et al., 2016; Lluch et al., 2014). For these reasons, it is of interest to investigate on its relationship with postural oscillations.

The results of our study allow us to reject partially our first research hypothesis because the tongue position seems to not affect postural oscillations, while the second hypothesis concerning the relationship between the degrees of freedom of neck and the stability seems confirmed.

To find out better results and to exclude possible errors the group was divided in two subgroups: 1) 7 subjects without swallowing disorders (WTSD), 2) 6 subjects with swallowing disorders (WSD). A skilled professional performed the evaluation of the swallowing and it is useful to understand whether a different postural behaviour can be present in case of swallowing disorders. The results in Table 1, that show no difference between these two groups, suggest the absence of any difference in postural oscillations in our study group. This outcome is fundamental to discuss because this aspect can be read from a twofold point of view: on one hand, the effect of swallowing disorders on postural control seems to be not present; and on the other hand, this lack of difference allow us to use the entire sample instead to create differences for any parameters between WTSD and WSD subjects. We obtained the same results also for cervical ROM. In fact, no differences were found between WTSD and WSD subjects for any ROM in any anatomical plane (Table 2). In this frame, swallowing disorders seem to not affect both postural control in standing position and motion of the head in the space.

In Table 1 is reported a lack of difference in postural oscillations also for different tongue position. Comfortable tongue position (CT), palatal spot position (ST), and low tongue position (LT) showed very similar values: $260.7 \pm 106.5 \mathrm{~mm} / 236.9 \pm 79.3 \mathrm{~mm} / 272.9 \pm 89.3 \mathrm{~mm}$ respectively. These results suggest that the use of different tongue position in clinical practice could not be relevant and that the difference in terms of results could be purely casual. To change voluntary the position of tongue seems to have no effect on postural oscillations. Hence, it is important to continue to collect data, by recruiting larger samples and comparing different subjects with usual different tongue position, in order to understand if this condition have a direct impact on postural behaviour.

The most important finding of this study is the significant correlation between cervical ROM and CoP sway path length (Figure 1). Higher degrees of freedom of the neck and lesser tension on cervical spine are significantly related to less postural oscillations. This is very interesting and useful for the daily clinical practice and for all professionals. The increase in the CoP sway path length in subjects with lower cervical ROM can be related to the higher fatigue of the tonic-postural system in order to compensate for the stiffness of cervical muscles. Based on the theory of the "inverted pendulum" (Winter, 1995) if the upper part of the body moves the lower part should compensate. Therefore, in case of stiffness in movement of the neck, the lower part should adopt some compensatory strategy and it could increase the CoP sway path length. In this frame, it could appear very useful to test cervical ROM during clinical practice because it can suggest limitation in other aspects connected with posture. 
Finally, we have to underline one open question: does the lack of difference in postural oscillations with different tongue position (and with swallowing disorders) depend from a real lack of interaction between body systems? Or does it depend from the sensibility of the instrumentation that is not able to discriminate little postural changes? Additional data collections are needed to answer this question.

We have to underline that this study has some limitations: first of all, the little sample or the absence of a test-retest procedure. However, it is a pilot study and the results suggest us the necessity to study more in deep this phenomenon with other specific class of subjects and with different methodology.

\section{CONCLUSION}

The position of the tongue is considered a very important issue by professionals in the field of posture and movement. However, in this pilot study we observed the lack of significant difference in postural oscillations with different tongue position. These results suggest us to continue the investigation on this field and further studies in this way should be performed in order to better understand the influence of this organ on body posture and human movement and to create a normative data.

It is very interesting the significant correlation between cervical ROM and CoP sway path length. This aspect opens a window on the research field about the interaction between different body areas in order to get and to maintain a proper health status.

\section{REFERENCES}

Alghadir, A. H., Zafar, H., \& lqbal, Z. A. (2015). Effect of tongue position on postural stability during quiet standing in healthy young males. Somatosens Mot Res, 32(3), 183-186. https://doi.org/10.3109/08990220.2015.1043120

Baldini, A., Nota, A., Cravino, G., Cioffi, C., Rinaldi, A., \& Cozza, P. (2013). Influence of vision and dental occlusion on body posture in pilots. Aviat Space Environ Med, 84(8), 823-827. https://doi.org/10.3357/ASEM.3541.2013

Battaglia, G., Giustino, V., lovane, A., Bellafiore, M., Martines, F., Patti, A., . . Palma, A. (2016). Influence of Occlusal Vertical Dimension on Cervical Spine Mobility in Sports Subjects. Acta Medica Mediterranea, 32(5), 1589-1595.

Battaglia, G., Messina, G., Giustino, V., Zangla, D., Barcellona, M., lovane, A., \& Palma, A. (2018). Influence of Vertical Dimension of Occlusion on Peak Force During Handgrip Tests in Athletes. Asian J Sports Med, 9(4), e68274. https://doi.org/10.5812/asjsm.68274

Carini, F., Mazzola, M., Fici, C., Palmeri, S., Messina, M., Damiani, P., \& Tomasello, G. (2017). Posture and posturology, anatomical and physiological profiles: overview and current state of art. Acta Biomed, 88(1), 11-16.

Celenay, S. T., Akbayrak, T., \& Kaya, D. O. (2016). A Comparison of the Effects of Stabilization Exercises Plus Manual Therapy to Those of Stabilization Exercises Alone in Patients With Nonspecific Mechanical Neck Pain: A Randomized Clinical Trial. J Orthop Sports Phys Ther, 46(2), 44-55. https://doi.org/10.2519/jospt.2016.5979

Chen, X., \& Qu, X. (2017). Influence of affective auditory stimuli on balance control during static stance. Ergonomics, 60(3), 404-409. https://doi.org/10.1080/00140139.2016.1182649

Gonzalez, P., Martlnez, M. B., Sierra, V., Rueda, Z. V., \& Botero-Mariaca, P. (2019). Tongue position assessment during oral phase deglutition in children with anterior open bite and normal vertical 
overbite. J Indian Soc Pedod Prev Dent, 37(2), 167-171. https://doi.org/10.4103/JISPPD.JISPPD_333 18

Julia-Sanchez, S., Alvarez-Herms, J., \& Burtscher, M. (2019). Dental occlusion and body balance: A question of environmental constraints? J Oral Rehabil, 46(4), 388-397. https://doi.org/10.1111/joor.12767

Kapteyn, T. S., Bles, W., Njiokiktjien, C. J., Kodde, L., Massen, C. H., \& Mol, J. M. (1983). Standardization in platform stabilometry being a part of posturography. Agressologie, 24(7), 321-326.

Lluch, E., Schomacher, J., Gizzi, L., Petzke, F., Seegar, D., \& Falla, D. (2014). Immediate effects of active cranio-cervical flexion exercise versus passive mobilisation of the upper cervical spine on pain and performance on the cranio-cervical flexion test. Man Ther, 19(1), 25-31. https://doi.org/10.1016/j.math.2013.05.011

Messina, G. (2017). The Tongue, Mandible, Hyoid System. Eur J Transl Myol, 27(1), 74-76. https://doi.org/10.4081/ejtm.2017.6363

Messina, G. (2020). The role of the styloid apophysis of the temporal bone in the biomechanics of the tongue, mandible, hyoid system: a case study. Eur J Transl Myol, 30(1), 8808. https://doi.org/10.4081/ejtm.2019.8808

Myers, T. W. (2001). Anatomy Trains: Myofascial Meridians for Manual and Movement Therapists (1st ed.): Churchill Livingstone.

Perinetti, G., Contardo, L., Silvestrini-Biavati, A., Perdoni, L., \& Castaldo, A. (2010). Dental malocclusion and body posture in young subjects: a multiple regression study. Clinics (Sao Paulo), 65(7), 689695. https://doi.org/10.1590/S1807-59322010000700007

Peterka, R. J. (2018). Sensory integration for human balance control. Handb Clin Neurol, 159, $27-42$. https://doi.org/10.1016/B978-0-444-63916-5.00002-1

Proske, U., \& Gandevia, S. C. (2012). The proprioceptive senses: their roles in signaling body shape, body position and movement, and muscle force. Physiol Rev, 92(4), 1651-1697. https://doi.org/10.1152/physrev.00048.2011

Romero-Franco, N., Martinez-Lopez, E. J., Lomas-Vega, R., Hita-Contreras, F., Osuna-Perez, M. C., \& Martinez-Amat, A. (2013). Short-term effects of proprioceptive training with unstable platform on

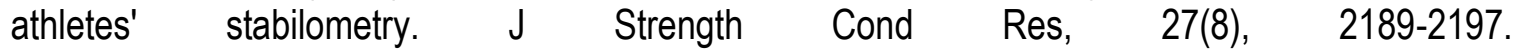
https://doi.org/10.1519/JSC.0b013e31827de04c

Russo, L., Bartolucci, P., Ardigò, L., Padulo, J., Pausic, J., \& Dello lacono, A. (2018). An exploratory study on the acute effects of proprioceptive exercise and/or neuromuscular taping on balance performance. Asian J Sports Med, 9(2), e63020. https://doi.org/10.5812/asjsm.63020

Russo, L., D'Eramo, U., Padulo, J., Foti, C., Schiffer, R., \& Scoppa, F. (2015). Day-time effect on postural stability in young sportsmen. Muscles Ligaments Tendons J, 5(1), 38-42. https://doi.org/10.32098/mlti.01.2015.08

Shapiro, S. S., \& Wilk, M. B. (1965). An Analysis of Variance Test for Normality (Complete Samples). Biometrika, 52(3/4), 591-611. https://doi.org/10.1093/biomet/52.3-4.591

Solovykh, E. A. (2013). Coordination of the stomatognathic and postural system activities and their functional status. Bull Exp Biol Med, 155(1), 92-95. https://doi.org/10.1007/s10517-013-2088-2

Valentim, A. F., Furlan, R. M., Perilo, T. V., Motta, A. R., \& Casas, E. B. (2016). Relationship between perception of tongue position and measures of tongue force on the teeth. Codas, 28(5), 546-550. https://doi.org/10.1590/2317-1782/20162015256

Vuillerme, N., Pinsault, N., Chenu, O., Demongeot, J., Payan, Y., \& Danilov, Y. (2008). Sensory supplementation system based on electrotactile tongue biofeedback of head position for balance control. Neurosci Lett, 431(3), 206-210. https://doi.org/10.1016/..neulet.2007.11.049 
Wilke, J., Krause, F., Vogt, L., \& Banzer, W. (2016). What Is Evidence-Based About Myofascial Chains: A Systematic Review. Arch Phys Med Rehabil, 97(3), 454-461. https://doi.org/10.1016/.apmr.2015.07.023

Winter, D. A. (1995). Human balance and posture control during standing and walking. Gait and Posture, 3(4), 193-214. https://doi.org/10.1016/0966-6362(96)82849-9 